\title{
An Investigation into Logical Thinking Skills and Proof Writing Levels of Prospective Mathematics Teachers
}

\author{
Emine Özdemir ${ }^{1}$, Filiz Tuba Dikkartin Övez ${ }^{1}$ \\ ${ }^{1}$ Department of Mathematics Education, Faculty of Necatibey Education, Balıkesir University, Balikesir, Turkey \\ Correspondence: Emine Özdemir, Department of Mathematics Education, Faculty of Necatibey Education, Balıkesir \\ University, Balikesir, Turkey.
}

Received: November 23, 2016

Accepted: December 9, $2016 \quad$ Online Published: December 15, 2016

doi:10.11114/jets.v5i2.2005

URL: http://dx.doi.org/10.11114/jets.v5i2.2005

\begin{abstract}
The cognitive development of prospective teacher needs to be taken into estimate so that proofs are presented in forms that are potentially meaningful for them. This requires educators and mathematicians to rethink consider the use of types of proof related to the logical thinking improvement of the singular. The purpose of the study is to identify the proof writing levels of prospective teachers and to reveal the difference between varying proof writing levels and logical thinking skills. In this study mixed research design was used and the sample was selected through criterion sampling. "The Proof-Writing Scale" and "The Test of Logical Thinking" were used as data tools. The proofs written by the prospective teachers for the theorems included in the Proof-Writing Scale were subjected to a descriptive analysis. The proofs were assigned in accordance with Balacheff's taxonomy. As a result of the study, the distribution of the proofs written by the prospective mathematics teachers to the theorems was as follows: pragmatic proofs $(35 \%)$, intellectual proofs $(49 \%)$ and demonstration proofs (16\%). There was a significant difference, in terms of their logical thinking skills, among the prospective teachers who had varying levels of proof-writing.
\end{abstract}

Keywords: prospective mathematics teachers, logical thinking skills, balacheff's taxonomy, proof writing levels.

\section{Introduction}

With the growing amount of attention given to the role and significance of proofs in mathematics, research topics in mathematics education have started to include identifying the thinking processes and development of these processes of students of varying age groups are engaged in during the course of proving (Knuth, 2002; Stylianides, 2007). A particularly effective skill in the thinking process used for proving is logical thinking. According to Piaget, logical thinking refers to the mental operations one uses in the face of certain problems (Karplus \& Butts, 1977). Logical thinking is set forth as one of the characteristics of Piaget's concrete operational stage and abstract operational stage. In the abstract operational stage, which involves proving, the student uses certain mental operations to solve a problem or to reach abstractions and generalizations (Altıparmak \& Öziş, 2005). Components of logical thinking, namely "controlling variables", "proportional reasoning", "probabilistic reasoning", "correlational reasoning" and "combinatorial reasoning", are described as skills required for achievement in mathematics courses (Lawson, 1992; Valanides, 1996; 1997).

When students have moved from the pre-school stage to the late abstract operational stage, they are expected to have acquired the ability to think logically, be aware of proving, make mathematical predictions, develop mathematical causes and proofs, evaluate, choose from various ways of logical thinking and types of proof and use different kinds of proof National Council of Teachers of Mathematics (NCTM, 2000). In the literature, many classifications, types and methods of proof have been identified and it is apparent that such classifications are heavily based on the stages of cognitive development put forward by Piaget (e.g. Tall, 1999; Balacheff, 1988; Sowder \& Harel, 1998; Stylianides \& Stylianides, 2009). The pre-school period, which Piaget calls the intuitive stage, is when the foundations for logical thinking and the concept of proof are laid. Classification, matching, ordering and comparison are the fundamental concepts of proof and these function as a bridge to transition into logical thinking (Aktaş, 2002; Altıparmak \& Öziş, 2005). In view of the characteristics of cognitive development, National Council of Teachers of Mathematics listed the requirements for the development of reasoning and proof-writing process as follows: Students should,

- understand that reasoning and proving are principal components of mathematics; 
- make and test mathematical predictions;

- assess and improve mathematical discussions and proofs;

- know various types of reasoning and be able to choose from and use methods of proof required for the process of testing.

A review of the mathematics curriculums for any grade in schools in Turkey, which have been gradually revised since 2005 and updated in 2013, suggests that the concept of proof is not directly incorporated into the curricula for primary and secondary schools but that an attempt is made to teach the concept of proof through the skills of reasoning and correlation, both of which are mathematical process skills also specified in the National Council of Teachers of Mathematics standards Ministry of National Education (MNE, 2015; NCTM, 2000). In fact, reasoning is described in these curricula as the process by which new information is acquired based on present information using materials of mathematics (symbols, definitions, relations, etc.) and thinking techniques (induction, deduction, comparison, generalization, etc.) unique to mathematics. In this respect, some of the indicators to be taken into consideration in efforts to enable students to acquire the skill of reasoning are

- arguing for the accuracy and validity of deductions;

- making logical generalizations and deductions;

- explaining and using mathematical patterns and relations when analyzing a mathematical situation.

Activities for enabling students to acquire the skills of reasoning and association are included, though with varying degrees of focus, in each learning domain of the curricula for primary and elementary schools (MNE, 2015). The objective of the curriculum for high schools is to present informal situations to students and for them to move from this informal situation to a formal mathematical structure. In this way, the curriculum provides them with an opportunity to explore mathematical relations and to associate them with other concepts that call for a high-level of mathematical competence. The curriculum, for the first time, emphasizes the skill of proving among the process skills. This curriculum integrates attainments for the development of proof-writing ability and mathematical reasoning into some of its subjects, such as "Methods of Proof" in the learning domain of Logic, "Real Numbers, Logarithm, Induction and Series" in the learning domain of Algebra, "Matrix, Determinant and Linear Equation Systems" in Trigonometry formulas and in the learning domain of Linear Algebra and "Limit, Derivative and Integral" in the learning domain of Basic Mathematics (MNE, 2015). It is acknowledged that the competence of the teacher matters when it comes to enabling students to acquire reasoning, association and proof-writing skills, all of which are emphasized in mathematics curricula. In fact, "Subject Matter Competencies for Mathematics Teachers", published by Ministry of National Education, refers to "developing students' reasoning skills" and "developing students' association skills", the second and third items included in the competence domain of "developing mathematical skills" (Matematik Öğretmeni Özel Alan Yeterlikleri, 2008).

Although the proof and proving are expected to play much more important role in school mathematics, many research studies conducted in the last two decades have suggested that the students have serious difficulties with proof and proving (e.g., Bell, 1976; Chazan, 1993; Coe \& Ruthven, 1994; Healy \& Hoyles, 2000; İnam \& Uğurel, 2016; Mariotti, 2000; Porteous, 1990; Romero, García, \& Codina, 2015; Selden \& Selden, 2009; Senk, 1985; Solomon, 2006; Sowder \& Harel, 1998; Weber, 2001).

Research on the causes of these difficulties has demonstrated that there is a positive correlation between logical thinking and proof-writing skills (Johnson \& Lawson, 1998) and that any deficiency in the logical thinking skill tends to restrict the proof writing (Lawson, 1992). It is also reported that students know neither about definitions of proof nor how to use them (Edwards \& Ward, 2004; Knapp, 2005; Moore, 1994; Weber, 2006), that they fail to understand the nature of proof, mathematical rules, or techniques and strategies for proving (Gibson,1998; Weber, 2006), and that they cannot properly use logical evidence or mathematical language (Baker \& Campbell, 2004; Edwards \& Ward, 2004; Knapp, 2005; Moore, 1994).

Considering the principal objectives of mathematics curricula and the effects of proof-writing skill on mathematical reasoning, students can be trained to be satisfactorily competent at proof-writing and reasoning through teachers who have these two skills. If a mathematics teacher does not adequately understand the nature, techniques, strategies of proofs and mathematical language, they are likely to fail to train their students properly in this respect. Therefore, it is essential that teachers be aware of proof-writing skills, along with various types of proof-writing, seeing that they are responsible for perceiving their students' difficulties on writing proofs and for developing effective teaching methods. Otherwise, they might not take students' solutions into consideration by labeling a proof qualified in the literature as "not a proof".

In order that the objectives specified in the curriculum can be realized, it is crucial that teachers as well as prospective 
teachers have sufficient pedagogical content knowledge about proofs. Herein, the Taxonomy of Mathematical Proof, composed by Balacheff in accordance with students' stages of cognitive development, will hopefully prove to be a guide for teachers, in the broadest sense, in their attempts to assess proofs written by students (Nesher \& Kilpatrick, 1990).

Balacheff (1988) divided mathematical proofs into three levels, namely pragmatic proof, intellectual proof and demonstration proof. Pragmatic proofs, which exist at the lowest level, involve unrelated responses, proofs completely based on numerical examples- experimental arguments- leaving blank or responses based simply on the writing of what is given. Intellectual proofs, which are at the intermediate level, include proofs based on formulation- that is, proofs given through the use of incomplete mathematical language and demonstrations- or logical attempts to write proofs with a general argument. Demonstration, which is the highest level, is characterized by completely accurate proofs that have to be organized with a theory or the use of information commonly accepted by a community. Assessments of proofs written by students can draw on this classification. Balacheff's proof levels, organized according to students' stages of cognitive development, forms the theoretical basis for the study.

The purpose of the study is to identify the proof writing levels of prospective teachers and to reveal the difference between varying proof writing levels and logical thinking skills. The following research problems were posed accordingly:

1) What are proof writing levels of prospective teachers?

2) Is there a significant difference between prospective teachers' proof-writing levels and logical thinking skills?

\section{Method}

\subsection{Study Model}

The study used a mixed research design, a method which enables qualitative and quantitative approaches to be used in a collective or integrated manner (Creswell, 2008). As a qualitative side of the research design, a case study is used. In addition, the study also involved the use of a correlative survey method, which attempts to identify any possible correlation between two or more variables and to determine their significance and direction (Creswell, 2008).

\subsection{Participant}

The sample was selected through criterion sampling, one of the purposive sampling methods. The basic concept of criterion sampling method is the study of all cases that meet a set of predetermined criteria (Yıldırım \& Şimşek, 2005). Two criteria were specified for the study: The participants must be senior students attending the department of Elementary Mathematics Education at Balıkesir University University during the 2014-2015 academic year and they must have passed the Abstract Mathematics, Analysis I, II and III, and Introduction to Algebra courses. Students were at the age of 21. The sample was comprised of 53 ( 25 male, 28 female) participants randomly selected out of 130 prospective teachers who meet both of the criteria.

\subsection{Data Collection Instruments}

In this study to identify the prospective teachers' proof-writing levels, "The Proof-Writing Scale" and "the Test of Logical Thinking", which was developed by Tobin \& Capie (1981) and adapted to Turkish by Geban, Aşkar \& Özkan (1992) were used.

"The Proof-Writing Scale" is comprised of 20 open-ended questions determined based on the theorems used in basic courses given at the department of Elementary Mathematics Teaching, such as Analysis, Algebra, and Abstract Mathematics. The theorems were submitted to five specialists who were teaching the courses, and they were asked to assess them in terms of language and comprehensibility and clarity of the questions.

The content validity was tested through Lawshe's (1975) technique (as cited in Yurdagül, 2005). Each item in the preliminary scale was rated in accordance with learned opinion as follows: "able to measure the targeted construct", "relevant to the construct but unnecessary", "able to partly measure the targeted construct", and "unable to measure the targeted construct". The content validity ratios were determined for the test items. In this way, four questions were observed to have content validity ratios of more than .78 (Veneziano \& Hooper, 1997) at the level of significance being $\alpha=0.05$.

The proofs written by the prospective teachers for the theorems included in the Proof-Writing Scale were separately analyzed by the researchers, and the reliability of the study was tested based on the reliability formula proposed by Miles \& Huberman (1994), namely "reliability $=$ number of agreements / (number of agreements + number of disagreements). The reliability, as calculated with the formula, was $98 \%$. Since the value was higher than $70 \%$, the reliability was confirmed (Miles \& Huberman, 1994). 
The theorems given in the scale were as follows:

1. Prove that the expression of $\sqrt{2}+\sqrt{3}$ is irrational.

2. Prove that the subset of a set with $n$ elements is $2 n$. ( $n \in N$ and $n$ is finite)

3. Prove that $\mathrm{AX}(\mathrm{BUC})$ is equal to (AXB) $\mathrm{U}$ (AXC).

4. Given that $f$ and $g$ are each functions, if the functions of $f(x)$ and $g(x)$ are 1-1, prove that fog $(x)$ is also 1-1.

The logical thinking skills of the prospective teachers were assessed through "The Test of Logical Thinking Skill", which was developed by Tobin \& Capie (1981) and adapted to Turkish by Geban, Aşkar \& Özkan (1992). The internal consistency coefficient (Cronbach's alpha) for the test was .81. The test consisted of two sections and contained 8 multiple-choice questions in addition to two open-ended questions. The minimum and maximum scores in the test were zero and ten respectively.

\subsection{Data Analysis}

The proofs written by the prospective teachers for the theorems included in the Proof-Writing Scale were subjected to a descriptive analysis, and the prospective teachers were assigned codes ranging from 1 to 53 by researchers who are expert in mathematics education at the department of elementary mathematics education in Balikesir University. The proofs were assigned a score of zero, one or two in accordance with Balacheff's taxonomy. According to this scoring, the prospective teachers' scores were rearranged based on Guttman's method and grouped under three groups (Guttman, 1946). For comparisons made through numerical measurements, the proof-writing score varied between zero and eight. Since the mean of the scores was two, the emerging distribution was as follows: the levels of demonstration proof (6-8), intellectual proof (3-5), and pragmatic proof (0-2). The differences between the prospective teachers' proof-writing scores and their logical thinking skills was measured through a one-way analysis of variance.

\section{Results}

\subsection{The Findings on the First Research Problem}

In order to identify the extent to which the prospective teachers could write proofs the proofs they wrote were assessed in accordance with Balacheff's Taxonomy of Mathematical Proof, and they were labeled under one of the following three levels: pragmatic proof, intellectual proof and demonstration. Table 1 presents the frequencies and percentages for the proof writing levels.

Table 1. Distribution of prospective teachers' proof writing levels

\begin{tabular}{lllllll}
\hline \multirow{2}{*}{ Theorems } & \multicolumn{2}{c}{ Pragmatic proof } & \multicolumn{2}{c}{ Intellectual proof } & \multicolumn{2}{l}{ Demonstration proof } \\
\cline { 2 - 7 } & $\mathrm{f}$ & $\%$ & $\mathrm{f}$ & $\%$ & $\mathrm{f}$ & $\%$ \\
\hline 1. theorem & 36 & 68 & 15 & 28 & 2 & 4 \\
2. theorem & 38 & 72 & 13 & 25 & 2 & 3 \\
3. theorem & 16 & 30 & 13 & 25 & 24 & 45 \\
4. theorem & 43 & 81 & 6 & 11 & 4 & 8 \\
\hline
\end{tabular}

The distribution of the proofs written by the prospective teachers according to the three levels was as follows: pragmatic proofs $(63 \%)$, intellectual proofs $(22 \%)$ and demonstration proof $(15 \%)$. In their attempts to prove the irrationality of $\sqrt{2}+\sqrt{3}$ (the first theorem), only two of the prospective teachers were observed to have understood the theorem correctly, to have established the hypothesis accurately and to have accomplished the stages verification, generalization, association and deduction. In addition, they used mathematical language and definitions in a proper way, and their preferred method of proving was reductio ad absurdum. The finding suggested that only two of the prospective teachers were able to write proofs at the level of demonstration proof. One of the proofs written by the two prospective teachers regarding the first theorem is presented in Figure 1.

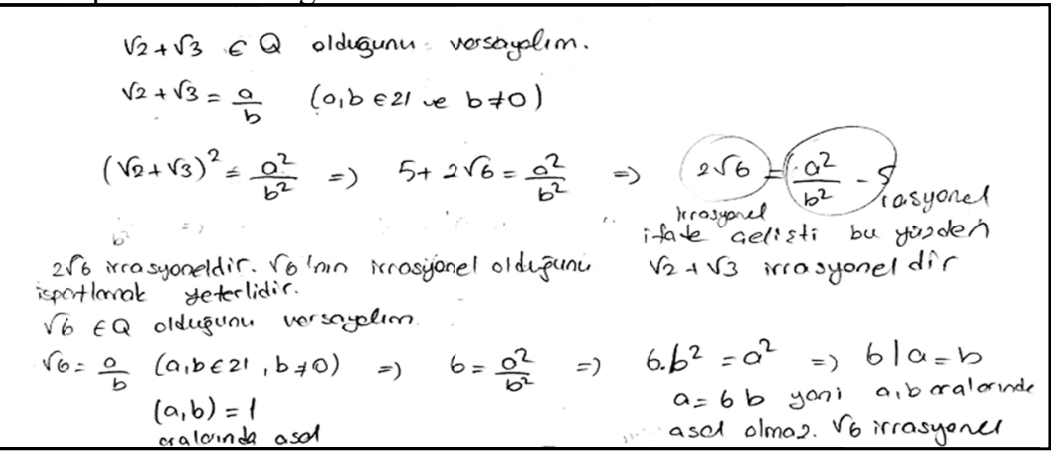

Figure 1. Proof samples of the first theorem in the demonstration proof 
Out of all the prospective teachers, $28 \%$ used reductio ad absurdum in their attempts to write a proof for the first theorem; even so, their proofs were incomplete. Those who provided an intellectual proof did so based on formulation. In other words, their proofs were based on memorization. Since they failed to fully understand the theorem and thereby set up false hypothesis, they wrongly assumed that they had fully proven the first theorem by showing the irrationality of $\sqrt{2}$ and/or $\sqrt{3}$ and it was determined that the had deficiencies in using mathematical language. An example of this is given in Figure 2.

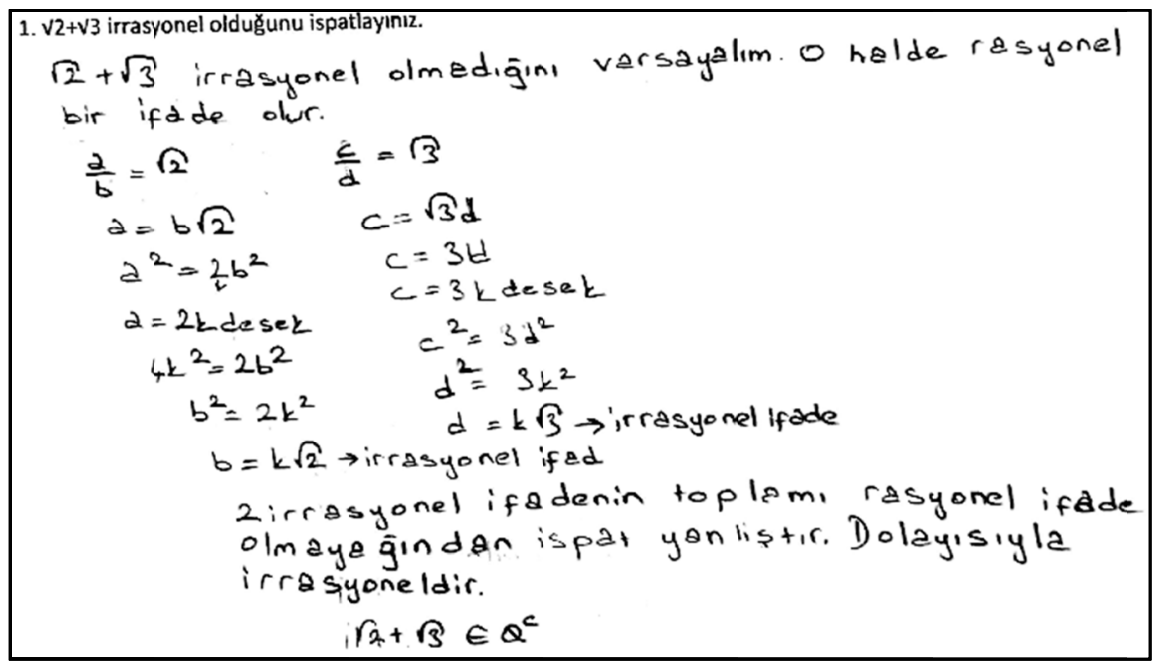

Figure 2. Proof samples of the first theorem in the intellectual proof

As examined the example in Figure 2, although the prospective teacher chose to use reductio ad absurdum when they started their proof-writing and accepted that $\sqrt{2}+\sqrt{3}$ was rational, they could establish the hypothesis correctly but directly showed that $\sqrt{2}$ and $\sqrt{3}$ were irrational. Afterwards, they finalized their proof-writing with the statement, "the proof is wrong because the sum of two irrational statement cannot yield a rational statement; therefore, the initial proposition is wrong, and they reached the conclusion of $\sqrt{2}+\sqrt{3} \in Q^{c}$ ". In other words, the prospective teacher failed to understand the theorem correctly, to establish the hypothesis accurately and to understand the logic of the stages of verification, generalization, association, and deduction. On the contrary, they should have proven "the sum of two irrational expressions cannot yield a rational expression" and finalized their proof-writing by adding that they had identified a contradiction. Pragmatic proofs involve unrelated responses, proofs completely based on numerical examples- experimental arguments-, leaving blank, or responses simply based on the writing of what is given. Figure 3 presents the most typical of the pragmatic proofs written for the first theorem. It is clear from the example that the prospective teacher provided an unrelated response.

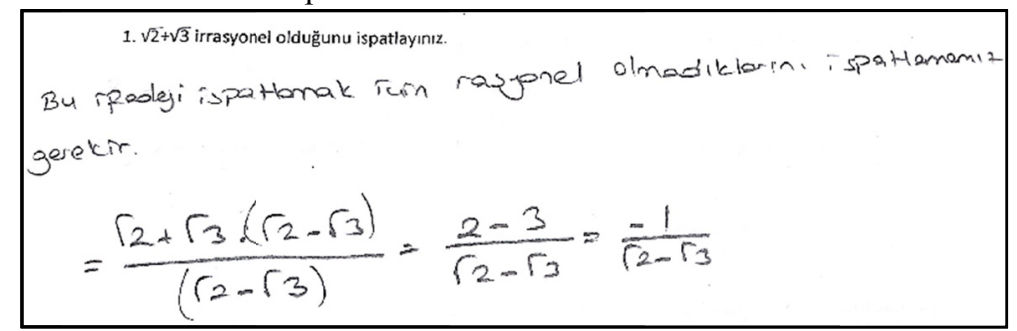

Figure 3. Proof samples of the first theorem in the pragmatic proof

A review of the responses regarding the second theorem suggested that those prospective teachers who provided an intellectual proof largely chose to write a proof based on induction yet failed to complete their proofs. On the other hand, some of the prospective teachers who wrote a pragmatic proof assumed that they had proven the second theorem by providing the binomial expansion of the expression $2^{\mathrm{n}}$. Others seemed to form generalizations by assigning numerical values to the variable " $n$ " in the expression $2^{n}$. Figure 4 presents examples of proofs for the second theorem at all three levels. 


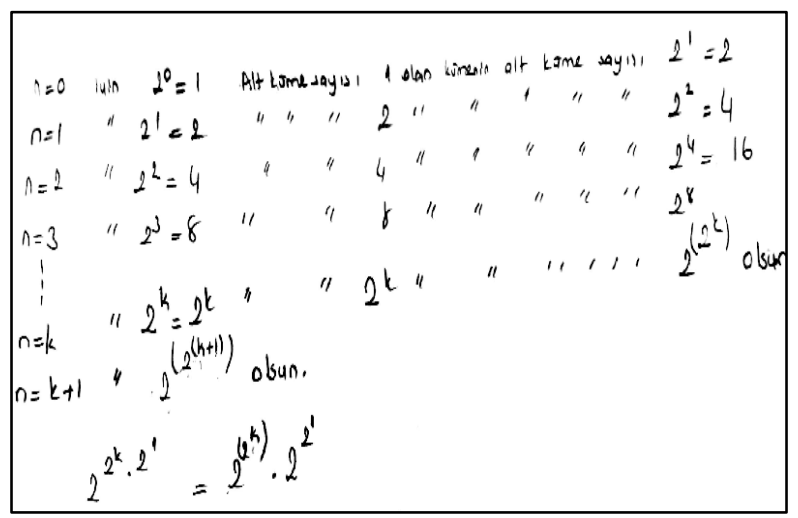

The proof written by $\mathrm{S}_{48}$ is an example of intellectual proofs. He preferred to use an inductive method of proving yet could not finalize the proof accurately since he did not show the accuracy of the expression for $\mathrm{n}=\mathrm{k}+1$.

$$
\begin{aligned}
& \left(\begin{array}{l}
n \\
0
\end{array}\right)+\left(\begin{array}{l}
n \\
1
\end{array}\right)+\left(\begin{array}{l}
n \\
2
\end{array}\right)+\left(\begin{array}{l}
n \\
3
\end{array}\right)+\cdots+\left(\begin{array}{l}
n \\
n
\end{array}\right) \\
& \left(\begin{array}{l}
x \\
y
\end{array}\right)=x^{n} y^{n}+x^{n-1} \cdot y+x^{n-2} y+\cdots+x^{0} y^{n} \\
& x=1 \quad y=1 \text { vesilise formüben gelde edilir }
\end{aligned}
$$

Figure 4. Proof samples of the second theorem in the pragmatic and intellectual proofs

Levels

The responses to the third theorem suggested that those who gave an intellectual proof generally proved the theorem irreversible and that they did not take the necessity of reversible into account in the presentation of the equation. An example of this would be the proof written by $S_{1}$. On the other hand, those who provided a pragmatic proof started out their proof-writing in error, as they were unable to properly understand the notion of Cartesian product. The proof written by $\mathrm{S}_{47}$ used the three special sets selected and showed the distributive property on the associative operation of the Cartesian product but did not provide a proof. The proof written by $\mathrm{S}_{32}$ was an example of demonstration proof. $\mathrm{S}_{32}$ chose the direct method of proof and was able to properly use mathematical language and the definitions of Cartesian product. Examples of proofs written for the third theorem are presented in Figure 5.

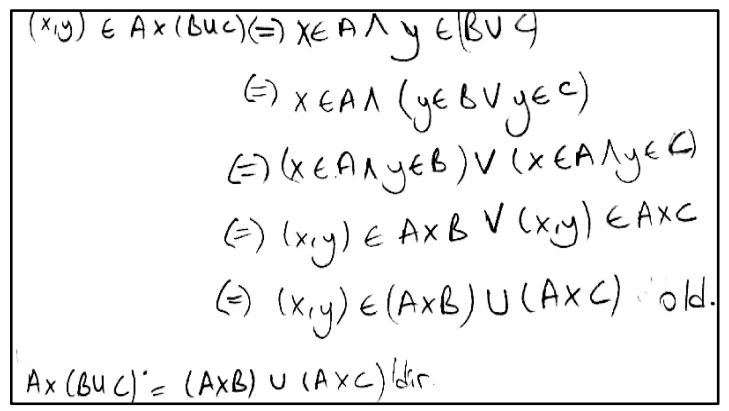

The proof written by $\mathrm{S}_{32}$ is an example of demonstration proof.

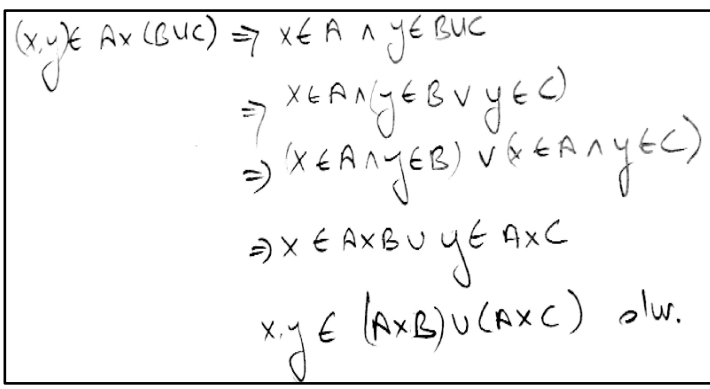

The proof written by $\mathrm{S}_{1}$ is an example of intellectual proof.

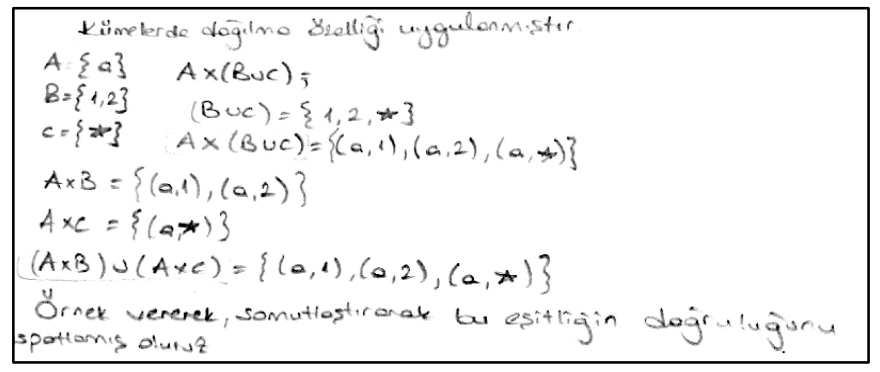

The proof written by $\mathrm{S}_{47}$ is an example of pragmatic proof.

Figure 5. Proof samples of the third theorem at all three levels

The distribution of the responses to the fourth theorem according to the three levels was as follows: demonstration proof 
$(8 \%)$, intellectual proofs $(11 \%)$ and pragmatic proofs $(81 \%)$. Figure 6 presents examples of proofs for the fourth theorem at all three levels.

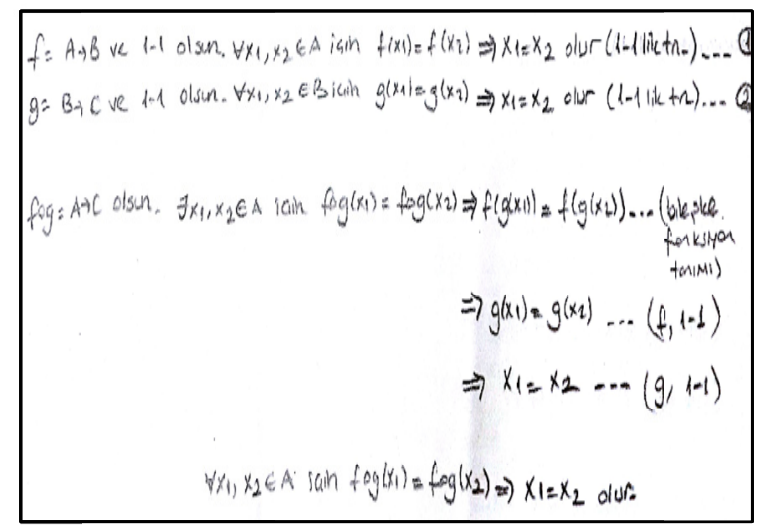

The proof written by $S_{15}$ is an example of demonstration proof.

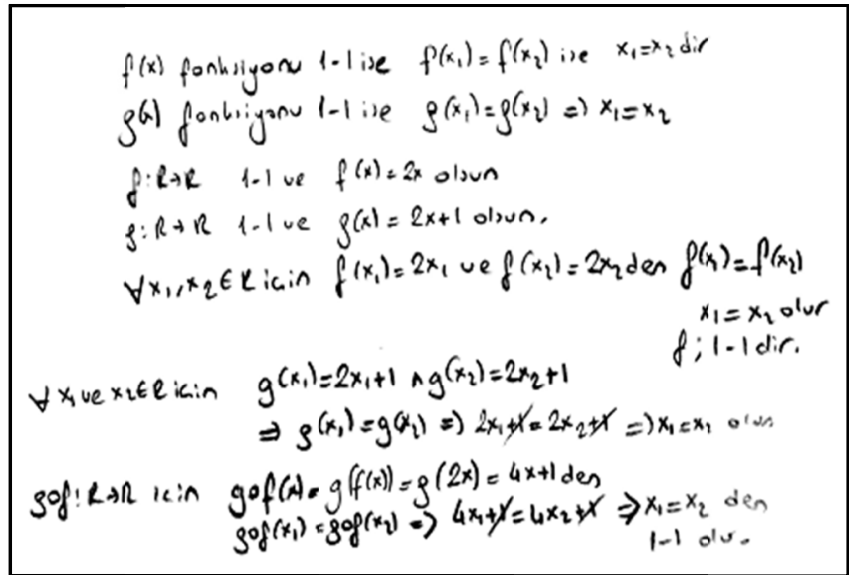

The proof written by $\mathrm{S}_{45}$ is an example of pragmatic proof.

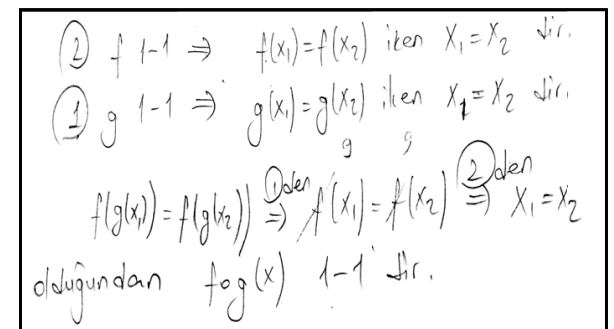

The proof written by $\mathrm{S}_{46}$ is an example of intellectual proofs.

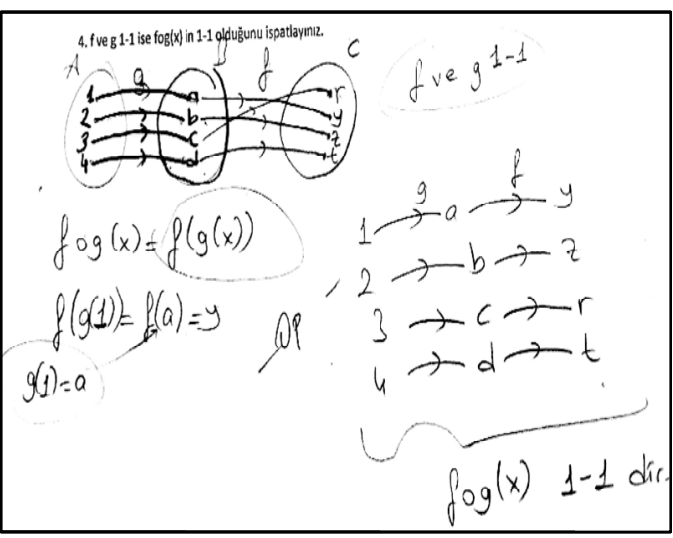

The proof written by $\mathrm{S}_{39}$ is an example of pragmatic proof.

Figure 6. Proof samples of the fourth theorem at all three levels

The responses to the fourth theorem suggested that those prospective teachers who were able to write a proof at the level of demonstration were able to properly describe the property of injective (one-to-one) of the functions and accurately define composite function. Having established the hypothesis accurately, these prospective teachers used the properties of injective (one-to-one) of the functions $\mathrm{f}$ and $\mathrm{g}$ and were able to prove, as desired, that the composite function was one-to-one. An example of this would be the proof presented by $S_{15}$.

As for those who provided an intellectual proof to the theorem, they used incomplete mathematical language and expressions regarding the property of injective of the function and definition of a composite function, and also failed to arrive at a proof with a general argument. As an example of this condition, it can be said that $\mathrm{S}_{46}$ had misconceptions about composite functions and failed to associate property of one-to-one with the definition of composite function.

Some of the teachers writing a pragmatic proof confused the property of one-to-one of the function with property of well-defined and based their proofs on this confusion. Some of others chose two special one-to-one functions, showed the being one-to-one, and then either attempted to write a general argument or left blank for this step. Examples of the former and latter situations would be the proofs written by $\mathrm{S}_{39}$ and $\mathrm{S}_{45}$, respectively.

\subsection{Findings on the Second Research Problem}

This section was comprised of interpretive statistics in order to provide an answer to the second research problem. In this respecl, a one-way analysis of variance (Büyüköztürk, 2006) was used to identify whether the prospective teachers' logical thinking skills differed depending on their proofs. The results of the analysis are presented in Table 2. 
Table 2. Descriptive data related to proof writing levels and the results of the one-way analysis for variance

\begin{tabular}{llll}
\hline Proof Writing Levels & $X$ & $\mathrm{Sd}$ & $\mathrm{N}$ \\
\hline Demonstration proof & 9.08 & 1.01 & 9 \\
Intellectual proof & 6.15 & 1.15 & 26 \\
Pragmatic proof & 4.72 & 1.67 & 18 \\
Source of Variance & Sum of Squares & $\mathrm{df}$ & $\mathrm{F}$ \\
Between groups & 109.797 & 2 & 30.84 \\
Within groups & 88.99 & 50 & \\
Total & 198.792 & 52 & \\
\hline
\end{tabular}

The mean scores indicated a difference, in terms of their logical thinking scores, among the prospective teachers who had varying levels of proof-writing, and the difference favored those writing proofs at the level of demonstration proof (Table 2). A one-way ANOVA was conducted to test the significance of the difference. The results suggested that the prospective teachers' logical thinking scores significantly differed depending on the degrees of proof-writing level $[F(2-50)=30.84 ; \mathrm{p}<.05]$. A Scheffe's test, which is a multiple comparison test, was conducted to identify the source of the difference for the value F (Büyüköztürk, 2006). Table 3 presents the results of the Scheffe's test.

Table 3. Results of the scheffe test regarding the logical thinking scores of prospective teachers

\begin{tabular}{llll}
\hline (I) Proof Writing Levels & (J) Proof Writing Levels & (I-J)Mean Difference & $\mathrm{p}$ \\
\hline Pragmatic proof & Intellectual proof & $-1,43$ & .000 \\
Pragmatic proof & Demonstration proof & $-4,27$ & .000 \\
Intellectual proof & Demonstration proof & $-2,84$ & .000 \\
\hline
\end{tabular}

Those prospective teachers who wrote proofs at the level of demonstration had higher logical thinking scores when compared to those who provided intellectual or pragmatic proofs (Table 2). In other words, the participants writing proofs at the level of demonstration had the highest logical thinking scores, whereas those providing pragmatic proofs had the lowest logical thinking scores. To sum up, when the degree of proof-writing level increased, so did the logical thinking scores.

\section{Conclusion, Discussion and Implications}

As a result of the study, the distribution of the proofs written by the prospective mathematics teachers to the theorems was as follows: pragmatic proofs (35\%), intellectual proofs (49\%) and demonstration proofs $(16 \%)$. According to this result, most of the prospective teachers could write either intellectual or pragmatic proofs. These proofs were in the form of giving unrelated responses to the theorems, using numerical examples and experimental arguments or being unable to finalize the proof despite logical attempts based on formulation. The finding is also supported by the results of Özer and Arıkan (2002).

Most of the prospective teachers did not know the meaning of proof and considered their numerical examples or definitions as proofs. According to the examples of proofs provided by the prospective teachers regarding the fourth theorem, they assumed they had finalized their proofs by simply writing the definition of 1-1. Similarly, Raman (2001) reported that students tend to base their proofs on formal definitions, consider a solution more valid in the presence of formal definitions and have difficulty in distinguishing accurate proofs from inaccurate ones. Likewise, Jones (2000) demonstrated that mathematics teachers have a weak concept of proof. Furthermore, most of the prospective teachers writing intellectual proofs based their proofs on a deductive or inductive approach and failed to finalize their proofs. Presumably, the reason for this was that they attempted to follow a similar path to pre-memorized proofs without comprehending the logic of proofs. In fact, most of the intellectual proofs regarding the theorem "please write the irrationality of the expression $\sqrt{2}+\sqrt{3}$ " suggested that the prospective teachers simply copied the irrationality of $\sqrt{2}$ and $\sqrt{3}$ in the same manner as they had learned in the Analysis course, yet they failed to come up with a similar way to write a proof concerning the expression $\sqrt{2}+\sqrt{3}$. A similar finding was reported by Moralı, Uğurel, Türnüklü \&Yeşildere (2006), who noted that prospective teachers memorize proofs without understanding the logic of the theorems and proofs they have learned throughout their educational life.

Secondly, there was a significant difference, in terms of their logical thinking skills, among the prospective teachers who had varying degrees of proof-writing level. It was noteworthy that those prospective teachers who wrote proofs at the level of demonstration had higher logical thinking scores when compared to those providing intellectual or pragmatic proofs, evidence suggesting a positive difference between the logical thinking skills and the proof-writing levels. The finding is supported by research in the literature (Johnson \& Lawson, 1998; Lawson, 1992; Oliva, 2003).

Development of an understanding into the notion of proof is a central objective of school mathematics, especially in elementary mathematics education (Coe \& Ruthven, 1994; Selden \& Selden, 2009). The role of proof is to enhance mathematical understanding (Selden \& Selden, 2009). Moreover, proof not only fosters students' analytical and logical thinking skills but also provides them with opportunities to practice with their mathematical ideas (Herbst, 2002). 
Despite the role and significance of proofs in mathematics, it is well known that prospective teachers have severe difficulties in conducting proofs during the course of their university life and that their strategies for proving are generally insufficient (Almeida, 2000; Weber, 2001).

Studies have focused to identify the proof writing levels of prospective teachers and to reveal the difference between varying proof writing levels and logical thinking skills. In Turkey and also in literature there are only a few studies about investigation of the relation between proof writing levels and logical thinking skills. Because of the logic and logical thinking skills are important for proving, it is necessary to empower prospective teachers to have the confidence in proving logically. This research focused on it in order to determine prospective teachers more about logical thinking and to transition more smoothly into mathematical proofs. The implication of this research field of mathematics education is that it provides scaffolding for the prospective teachers to determine and teach how to write Balachef's proof writing levels acording to their logical thinking skills.

In this context, it is recommended that further studies be conducted on reasoning skills and proof-writing skills and levels so as to overcome difficulties students have in their proving attempts. In addition, students would perhaps benefit from the establishment of appropriate, stimulus-rich environments to improve their logical thinking skills.

\section{References}

Aktaş, Y. (2002). Mathematics education in preschool. Adana: Nobel Publication.

Almeida, D. (2000). A survey of mathematics undergraduates' interaction with proof: some implications form mathematics education. International Journal of Mathematical Education in Science and Technology, 31(6), 869-890. https://doi.org/10.1080/00207390050203360

Altıparmak, K., \& Öziş, T. (2005). An investigation upon mathematical proof and development of mathematical reasoning. Journal of Ege Education, 6(1), 25-37.

Baker, D., \& Campbell, C. (2004). Fostering the development of mathematical thinking: Observations from a proofs course. Primus, 14(4), 345-353. https://doi.org/10.1080/10511970408984098

Balacheff, N. (1988). Aspects of proof in pupils' practice of school mathematics. In D. Pimm (Ed.), Mathematics, teachers and children (pp. 216-230). London: Hodder \& Stoughton.

Bell, A. (1976). A study of pupils' proof-explanations in mathematical situations. Educational Studies in Mathematics, 7, 23-40. https://doi.org/10.1007/BF00144356

Büyüköztürk, S. (2006). Handbook of data analysis for social sciences. PegemA Publication. Ankara.

Chazan, D. (1993). High school geometry students' justification for their views of empirical evidence and mathematical proof. Educational Studies in Mathematics, 24(4), 359-387. https://doi.org/10.1007/BF01273371

Coe, R., \& Ruthven, K. (1994). Proof practices and construct of advances mathematics students. British Educational Research Journal, 20(1), 41-53. https://doi.org/10.1080/0141192940200105

Creswell, J. W. (2008). Educational research planning, conducting and evaluating quantitative and qualitative research. International Pearson Merril Prentice Hall.

Edwards, B. S., \& Ward, M. B. (2004). Surprises from mathematics education research: Student (mis)use of mathematical definitions. American Mathematical Monthly, 111(5), 411-424. https://doi.org/10.2307/4145268

Geban, Ö., Aşkar, P., \& Özkan, İ. (1992). Effects of computer simulated experiment and problem solving approaches on students learning outcomes at the high school level. Journal of Educational Research, 86(1) 5-10. https://doi.org/10.1080/00220671.1992.9941821

Gibson, D. (1998). Students' use of diagrams to develop proofs in an introductory analysis course. Students' proof schemes. In E. Dubinsky, A. Schoenfeld, \& J. Kaput (Eds.), Research in Collegiate Mathematics Education, III, 284-307. AMS. https://doi.org/10.1090/cbmath/007/08

Guttman, L. (1946). The test-retest reliability of qualitative data. Psychometrika, 11(2), 81-95. https://doi.org/10.1007/BF02288925

Healy, L., \& Hoyles, C. (2000). A study of proof conceptions in algebra. Journal for Research in Mathematics Education, 31(4), 396-428. https://doi.org/10.2307/749651

Herbst, P. (2002). Establishing a custom of proving in American school geometry: Evolution of the two-column proof in the early twentieth century. Educational Studies in Mathematics, 49(3), 283-312.

İnam, B., \& Uğurel, I. (2016). The difficulties towards proof comprehension tests in a teaching impilication and the ways that interfere the process. Mersin University Journal of the Faculty of Education, 12(1), 1-21. 
http://dx.doi.org/10.17860/efd.91329

Johnson, M. A., \& Lawson, A. E. (1998). What are the relative effects of reasoning ability and prior knowledge on biology achievement in expository and inquiry classes? Journal of Research in Science Teaching, 35(1), 89-103. https://doi.org/10.1002/(SICI)1098-2736(199801)35:1<89::AID-TEA6>3.0.CO;2-J

Jones, K. (2000). The student experience of mathematical proof at university level. International Journal of Mathematical Education in Science and Technology, 31(1), 53-60. https://doi.org/10.1080/002073900287381

Karplus, R., \& Butts, D. P. (1977). Science teaching and the development of reasoning. Journal of Research in Science Teaching, 14(2), 169-175. https://doi.org/10.1002/tea.3660140212

Knapp, J. (2005). Learning to prove in order to prove to learn. http://mathpost.asu.edu/ sjgm/issues/2005_spring/SJGM_knapp.pdf (accessed April 03, 2014).

Knuth, E. (2002). Secondary school mathematics teachers' conceptions of proof. Journal for Research in Mathematics Education, 33(5), 379-405. https://doi.org/10.2307/4149959

Lawson, A. E. (1992). The development of reasoning among college biology students- A review of research. Journal of College Science Teaching, 21, 338- 344. Lawson.

Mariotti, M. A. (2000). Introduction to proof: the mediation of a dynamic software environment. Educational Studies in Mathematics, 44, 25-53. https://doi.org/10.1023/A:1012733122556

Matematik Öğretmeni Özel Alan Yeterlikleri, (2008). http://otmg.meb.gov.tr/alanmatematik.html (accessed May 06, 2014)

Miles, M. B., \& Huberman, A. M. (1994). Qualitative data analysis: an expanded sourcebook. (2nd Edition). Calif.: SAGE Publications.

Moore, R. C. (1994). Making the transition to formal proof. Educational Studies in mathematics, 27, 249-266. https://doi.org/10.1007/BF01273731

Moralı, S., Uğurel, I., Türnüklü, E., \&Yeşildere, S. (2006). The views of the mathematics teachers on proving. Journal of Kastamonu Education, 14(1), 147-160.

National Council of Teachers of Mathematics [NCTM] (2000). Principles and Standards for School Mathematics. Reston, VA: Author.

Ministry of National Education [MNE] (2015). Secondary mathematics 9-12. Classes curriculum. Ministry of National Education, Education and Discipline Board, Devlet Kitapları Müdürlüğü Publication, Ankara.

Nesher, P., \& Kilpatrick, J. (1990). Mathematics and cognition: A research synthesis by the international group for the psychology of mathematics education (ICMI Studies). Cambridge University Press. https://doi.org/10.1017/cbo9781139013499

Oliva, J. M. (2003). The structural coherence of students' conceptions in mechanics and conceptual change. International Journal of Science Education, 25(5), 539-561. https://doi.org/10.1080/09500690210163242

Özer, Ö., \& Arıkan, A. (2002). Proving levels of students' in high school math class. Paper presented at the 5th congress of international science and mathematics education.

Porteous, K. (1990). What do children really believe? Educational Studies in Mathematics, 21(2), 589-598. https://doi.org/10.1007/BF00315946

Raman, M. (2001). Proof and justification in college calculus. (Unpublished doctoral dissertation). University of California, Berkeley.

Romero, I. M., Del Mar García, M., \& Codina, A. (2015). Developing Mathematical Competencies in Secondary Students by Introducing Dynamic Geometry Systems in the Classroom. Education and Science, 40(177). http://dx.doi.org/10.15390/EB.2015.2640

Selden, J., \& Selden, A. (2009). Understanding The Proof Construction Process. In F.-L Lin, F.-J. Hsieh, G. Hanna, ve M. de Villiers (Eds.), Proceedings of the ICMI Study 19 Conference: Proof and Proving in Mathematics Education, Vol. 2. (pp. 196-201). Taipei, Taiwan: The Department of Mathematics, National Taiwan Normal University.

Senk, S. (1985). How well do students write geometry proofs? Mathematics Teacher, 78(6), 448-456.

Solomon, Y. (2006). Deficit or difference? The role of students' epistemologies of mathematics in their interaction in proof. Educational Studies in Mathematics, 61, 373-393. https://doi.org/10.1007/s10649-006-6927-1

Sowder, L., \& Harel, G. (1998). Types of Students' Justifications. Mathematics Teacher, 91(8), 670-675. 
Stylianides, A. J. (2007) The notion of proof in the context of elementary school mathematics. Educational Studies in Mathematics, 65(1), 1-20. https://doi.org/10.1007/s10649-006-9038-0

Stylianides, A. J., \& Stylianides, G. J. (2009). Proof constructions and evaluations. Educational Studies in Mathematics, 72(2), 237-253. https://doi.org/10.1007/s10649-009-9191-3

Tall, D. O. (1999). The cognitive development of proof: Is mathematical proof for all or for some? In Z. Usiskin (Ed.), Developments in School Mathematics Education Around the World, 4, 117-136. Reston, Virginia: NCTM.

Tobin, K., \& Capie, W. (1981). Development and validation of a group test of logical thinking. Educational and Psychological Measurement, 41(2), 413-424. https://doi.org/10.1177/001316448104100220

Valanides, N. C. (1996). Formal reasoning and science teaching. School Science and Mathematics, 96(2), 99-111. https://doi.org/10.1111/j.1949-8594.1996.tb15818.x

Valanides, N. C. (1997). Formal reasoning abilities and school achievement. Studies in Educational Evaluation, 23(2), 169-185. https://doi.org/10.1016/S0191-491X(97)00011-4

Veneziano, L., \& Hooper, J. A. (1997). Method for quantifying content validity of health-related questionnaires. Am $J$ Health Behav, 21(1), 67-70.

Weber, K. (2001). Student Difficulty in Constructing Proofs: The Need for Strategic Knowledge. Educational Studies in Mathematics, 48, 101-119. https://doi.org/10.1023/A:1015535614355

Weber, K. (2006). Investigating and teaching the processes used to construct proofs. In F.Hitt, G. Harel \& A. Selden (Eds), Research in Collegiate Mathematics Education, VI, 197-232. AMS. https://doi.org/10.1090/cbmath/013/07

Yıldırım, A., \& Şimşek, H. (2005). Qualitative research methods in the social sciences. Ankara: Seçkin Publication.

Yurdagül, H. (2005). Using content validity indices for content validation in scale development studies. Presented at the XIV. Conference on Educational Sciences. http://yunus.hacettepe.edu.tr/ yurdugul/3/indir/PamukkaleBildiri.pdf (accesesd on April 05, 2014).

\section{Copyrights}

Copyright for this article is retained by the author(s), with first publication rights granted to the journal.

This is an open-access article distributed under the terms and conditions of the Creative Commons Attribution license which permits unrestricted use, distribution, and reproduction in any medium, provided the original work is properly cited. 